OPEN ACCESS

Edited by:

Rafaqat Ali Gill,

Oil Crops Research Institute, Chinese Academy of Agricultural Sciences

(CAAS), China

Reviewed by:

Deepak Kumar Verma,

Indian Institute of Technology

Kharagpur, India

Muhammad Azhar Nadeem,

Sivas University of Science

and Technology, Turkey

Basharat Ali

University of Agriculture, Faisalabad,

Pakistan

${ }^{*}$ Correspondence: Xiaorong Wan

bioxrwan@hotmail.com

Yixiong Zheng

gdsscqs@163.com

Specialty section:

This article was submitted to

Plant Nutrition,

a section of the journal

Frontiers in Plant Science

Received: 01 November 2021 Accepted: 20 December 2021

Published: 08 February 2022

Citation:

Bao G, Zhou Q, Li S, Ashraf U, Huang S, Miao A, Cheng Z, Wan $X$ and Zheng Y (2022) Transcriptome Analysis Revealed the Mechanisms

Involved in Ultrasonic Seed

Treatment-Induced Aluminum

Tolerance in Peanut.

Front. Plant Sci. 12:807021.

doi: 10.3389/fpls.2021.807021

\section{Transcriptome Analysis Revealed the Mechanisms Involved in Ultrasonic Seed Treatment-Induced Aluminum Tolerance in Peanut}

\author{
Gegen Bao' ${ }^{1}$ Qi Zhou', Shengyu Li', Umair Ashraf', Suihua Huang ${ }^{3}$, Aimin Miao', \\ Zhishang Cheng ${ }^{4}$, Xiaorong Wan ${ }^{1 *}$ and Yixiong Zheng ${ }^{1 *}$ \\ ${ }^{1}$ Guangzhou Key Laboratory for Research and Development of Crop Germplasm Resources, Zhongkai University \\ of Agriculture and Engineering, Guangzhou, China, ${ }^{2}$ Department of Botany, Division of Science and Technology, University \\ of Education, Lahore, Pakistan, ${ }^{3}$ State Key Laboratory for Conservation and Utilization of Subtropical Agro-Bioresources, \\ College of Agriculture, South China Aricultural University, Guangzhou, China, ${ }^{4}$ College of Automation, Zhongkai University \\ of Agriculture and Engineering, Guangzhou, China
}

Ultrasonic (US) treatment is an efficient method to induce crop tolerance against heavy metal toxicity; however, US-induced aluminum (Al) tolerance in peanuts was rarely studied. This study was comprised of two treatments, namely, CK, without ultrasonic treatment, and US, an ultrasonic seed treatment, for $15 \mathrm{~min}$. Both treated and nontreated treatments were applied with $\mathrm{Al}$ in the form of $\mathrm{AlCl}_{3} .18 \mathrm{H}_{2} \mathrm{O}$ at $5 \mathrm{mmol} \mathrm{L}^{-1}$ in Hoagland solution at one leaf stage. Results depicted that plant height, main root length, and number of lateral roots increased significantly under US treatment. Transcriptome analysis revealed that plant hormone signal transduction and transcription factors (TFS) were significantly enriched in the differentially expressed genes (DEGs) in US treatment, and the plant hormones were measured, including salicylic acid (SA) and abscisic acid (ABA) contents, were substantially increased, while indole acetic acid (IAA) and jasmonic acid (JA) contents were decreased significantly in US treatment. The TFs were verified using quantitative real-time (qRT)-PCR, and it was found that multiple TFs genes were significantly upregulated in US treatment, and ALMT9 and FRDL1 genes were also significantly upregulated in US treatment. Overall, the US treatment induced the regulation of hormone content and regulated gene expression by regulating TFs to improve Al tolerance in peanuts. This study provided a theoretical rationale for US treatment to improve Al tolerance in peanuts.

Keywords: aluminum, peanut, growth, gene expression, transcription factor genes

\section{INTRODUCTION}

As much as $40-50 \%$ of the potentially arable lands are acidic in the world, and more than $40 \%$ of the arable lands in China are acidic soil, distributed in South China, with a total area of $2.04 \times 10^{7} \mathrm{~km}$, including Guangdong Province (Kochian et al., 2015; Li, 2019). Aluminum (Al) is the most abundant metal element in nature, accounting for $7.45 \%$ of the total weight of the crust of the earth, and exists in a dormant state. When the soil was acidified $(p H \leq 5.5), \mathrm{Al}^{3+}$ would be 
released. When the $\mathrm{pH}$ was $<4.3$, a large amount of $\mathrm{Al}^{3+}$ would be released, which would cause harmful effects on plants (Han et al., 2020). The soil types in southern China were mainly red soil, latosol soil, and yellow-brown soil (Yin, 2017). The total nitrogen content of the soil was generally $0.04-0.18 \%$. The inorganic phosphorus was mainly iron phosphate and aluminum salt. The total phosphorus content of red soil was generally $0.01-0.03 \%$, and the total potassium content was $0.9-0.4 \%$, respectively. Most of the trace elements in the soil were in the form of inorganic salts (Zhu et al., 2005). As the desilication and aluminization process of red soil is a slow acidification process, it is also affected by acid rain, environmental pollution, and farming methods. In the second soil survey, the $\mathrm{pH}$ of the soil was mostly 6.0-6.5 in South China. The current soil fertility monitoring results showed that the $\mathrm{pH}$ of the soil had dropped by $0.2-0.5 \mathrm{pH}$ units ( $\mathrm{Li}$ et al., 2013). At the same time, the acidic red soil in this area was dominated by kaolin. The cation exchange capacity was low, and the acid buffer capacity was weak. In addition, the temperature in this area was relatively high, and organic matter was easily decomposed, which made less contribution to the acid buffer capacity (Li et al., 2013). Peanut (Arachis hypogea L.) is among the four major oil crops with great economic importance (Liu et al., 2020). The growth and development of peanuts had been impaired by Al toxicity for a long time in South China, and the average yield had been reduced by more than $20 \%$ which is the most important reason for low peanut yield in this region than the national average (Zhang et al., 2009; Zhang and $\mathrm{Hu}, 2020$ ).

Aluminum toxicity limits crop production in those parts of the world. The effects of Al toxicity on crops were manifold, and it was generally believed that the main site of Al toxicity was the root tip (Wang Y. Q. et al., 2020). On the one hand, it was possible to influence the transport of molecules across the membrane by changing the properties of the cell wall, thereby causing a disorder of the intracellular metabolic process (Singh et al., 2017). On the other hand, it restricted the absorption of essential elements such as magnesium $(\mathrm{Mg})$, phosphorus $(\mathrm{P})$, and molybdenum (Mo), thereby affecting plant growth (Rahman et al., 2018). In addition, Al also inhibited the ductility of the leaves, stomata closure, and photosynthesis (Rahman et al., 2018; Singh et al., 2021). Research on Al in peanuts was relatively rare. Al stress caused the peroxidation of root tip cell membrane lipids and resulted in damage to the plasma membrane. After the injury, the plasma membrane was overloaded with $\mathrm{Ca}^{2+}$, and cytochrome $\mathrm{C}$ was released into the cytoplasm to induce programmed death of root tip cells, thereby inhibiting root growth (Zhan et al., 2009; Yao et al., 2014). Generally, there are two mechanisms responsible for Al tolerance in plants. First, an exclusion mechanism involved the secretion of organic acids, phenolic compounds, phosphates, and so on for chelating $\mathrm{Al}^{3+}$ into non-toxic compounds, thus preventing them from entering into root cells (Liu, 2018; Fang et al., 2020; Chauhan et al., 2021). Second, the internal tolerance mechanism referred to that after $\mathrm{Al}^{3+}$ enters the cytoplasm, the $\mathrm{Al}^{3+}$ in the cells were transported to the vacuole through the transporter to isolate them from other organelles, and thus $\mathrm{Al}^{3+}$-induced disruptions to the plant body were reduced (Zhang X. et al., 2019; Dai et al., 2020; Quimbaya et al., 2020). Two transporter families related to organic acid secretion, namely, multidrug and toxic compound extrusion (MATE), which regulates the secretion of citric acid, and aluminum-activated malate transporter (ALMT), which regulates the secretion of malate to chelate $\mathrm{Al}^{3+}$, respectively. $\mathrm{Al}^{3+}$ entering the cytoplasm might be transported into the vacuole through the regulation of ALS1 or VALT1 genes (Zhang X. et al., 2019; Fang et al., 2020; Chauhan et al., 2021; Figure 1).

Ultrasonic (US) treatment involves low to medium frequency $(20-100 \mathrm{kHz})$ sound waves and is considered a cheap, safe, simple, and environment-friendly technology (Chen Y. P. et al., 2013). The application of ultrasound in agriculture was one of the research topics of applying new technologies in physics to largescale agricultural production in modern agriculture (Zheng et al., 2008; Zhu et al., 2008). A series of mechanical, high-pressure, thermal, electrochemical, photochemical, oxygen, enzyme, and biological effects caused by ultrasound on organisms could sterilize seeds, promote seed germination, and increase yields (Liu J. et al., 2016). The modifications in seed coats by US waves could enhance the seed germination rate and early growth of the plant (Sun et al., 2020). US treatment could also restore seed vigor by improving antioxidant activities, such as superoxide dismutase (SOD) and peroxidase (POD), and reducing malondialdehyde (MDA) content (Ali et al., 2013a,b; Huang et al., 2021). Moreover, US treatment had substantial regulatory effects in different crops, for instance, US treatment reduced lead $(\mathrm{Pb})$ accumulation in brown rice (Rao et al., 2018) and improved cadmium (Cd) tolerance in oilseed rape (Brassica campestris L.) (Rao et al., 2019). Studies on lupin (Lupinus polyphyllus) and buckwheat (Fagopyrum mill) showed that US treatment not only promoted seed germination but also improved antioxidant defense system (Zhang et al., 2015; Guo, 2016). Thus, employing US technology to treat seeds could effectively enhance the ability of the crop to resist various abiotic stresses and could prove to be a quality agricultural seed treatment method in future (Ge and Ren, 2019).

In addition, plant hormones, i.e., salicylic acid (SA), jasmonic acid (JA), ethylene, abscisic acid (ABA), and indole acetic acid (IAA), play a crucial role in responding to $\mathrm{Al}$ stress (Shen et al., 2004; Yang et al., 2016; Ye et al., 2018; Wang Z. R. et al., 2020). ROS induced by Al stress affects the homeostasis of IAA (Panda et al., 2009; Yuan et al., 2013b; Wang M. et al., 2019). The accumulation of ROS induced by Al stress changed the intracellular redox balance and polar transport of auxin by regulating the expression of PIN protein (Chapman et al., 2019; Swarup and Bhosale, 2019). Al stress enhanced the expression of JA receptor COI1 and JA signal regulator MYC2 (Yang et al., 2017). Exogenous application of IAA, cytokinin, and $\mathrm{ABA}$ positively affect $\mathrm{Al}$-induced root inhibition (Ranjan et al., 2021). Cytokinin and IAA participated in the regulation of the response process against $\mathrm{Al}$ stress synergistically ( $\mathrm{He}$ et al., 2012). Furthermore, transcription factors (TFs) such as STOP1, ART1, and WRKY were involved in the mechanism of Al tolerance in crops (Yamaji et al., 2009; Godon et al., 2019; Li C. et al., 2020). Previously, effects of Al stress on various crops have been widely reported; however, US-induced modifications in internal mechanisms responsible for $\mathrm{Al}$ tolerance in peanut were rarely reported. Therefore, this study was conducted to get insights into the mechanisms involved in US treatment-induced Al tolerance in peanuts. 


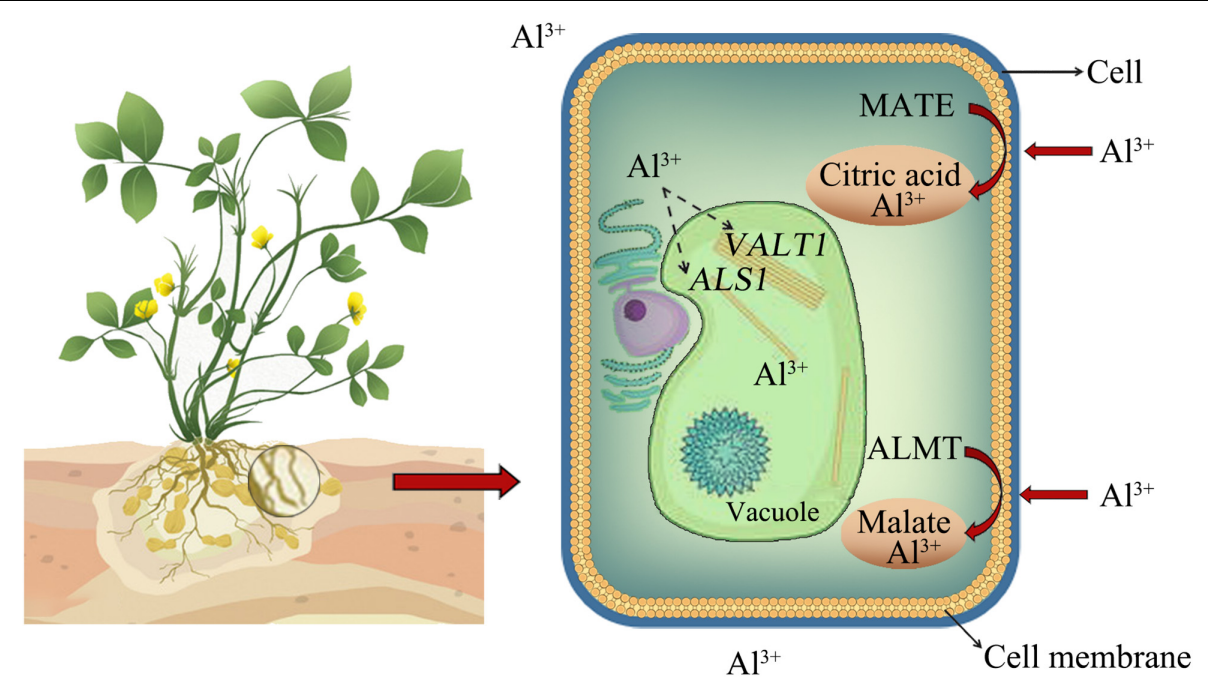

FIGURE 1 | External rejection mechanism of aluminum (Al) and internal tolerance mechanism. Organic acids could chelate Al3+ into non-toxic compounds, thereby preventing them from entering root cells. MATE regulates the secretion of citric acid, and ALMT regulates the secretion of malate to chelate Al3+. Al3+ entering the cytoplasm might be transported into the vacuole through the regulation of ALS1 or VALT1 genes (Zhang X. et al., 2019).

\section{MATERIALS AND METHODS}

\section{Experimental Setup}

The uniform seeds of peanut cultivar "Guihua58" were US treated for $15 \mathrm{~min}$ (at $20-40 \mathrm{kHz}$ frequency) using a small tunnel-type plant seed dry method ultrasonic treatment machine (5ZCG-T6, Golden Rice Agricultural Science and Technology Co. Ltd., Guangzhou, China) regarded as US and non-US treated seed regarded as CK. The experiment was conducted at the Guangzhou Key Laboratory for Research and Development of Crop Germplasm Resources, Zhongkai University of Agriculture and Engineering, Guangzhou, China (23104 N, 113281 E). Three statistical replicates of each treatment and $100 \mathrm{~g}$ of seeds per treatment were used. After treatment, peanut seeds were placed on a wet filter paper for 3 days to germinate, at a room temperature of $26^{\circ} \mathrm{C}$, and water was added to maintain moisture for 3 days. The seeds with uniform germination were selected and sown in a petri dish with twenty capsules in each petri dish. After culturing for 3 days, the seedlings were transferred to Hoagland nutrient solution containing plastic culture bowls. When the seedlings grew to one leaf and one heart stage ( 8 days of growth), the $\mathrm{AlCl}_{3} \cdot 18 \mathrm{H}_{2} \mathrm{O}$ $\left(5 \mathrm{mmol} \mathrm{L}^{-1}\right.$ ) was added to the nutrient solution for Al stress treatment. The nutrient solution was replaced once in every 3 days. The experiment was conducted at room temperature with $12 \mathrm{~h}$ day/12 $\mathrm{h}$ night photoperiod. The seedlings were harvested 5 days after $\mathrm{Al}$ treatment for the determination of morphological traits, Al contents, as well as biochemical and molecular analyses.

\section{Morphological Traits}

Plant height and main root length were determined after harvesting of seedlings using a scale from all the treatments and averaged. The number of lateral roots of each seedling was counted from each treatment and averaged.

\section{Determination of Aluminum Concentration}

The dried sample $(0.2 \mathrm{~g})$ in powder form was digested with diacidic mixture of $\mathrm{HClO}_{4}: \mathrm{HNO}_{3}(1: 4 \mathrm{v} / \mathrm{v})$ for $4 \mathrm{~h}$, and the volume was adjusted to $25 \mathrm{ml}$ after filtration. The $\mathrm{Al}$ contents in the sample were measured using Atomic Absorption Spectrophotometer (AA6300C, Shimadzu, Japan) (Ashraf et al., 2017; Bao et al., 2021).

\section{Transcriptome Sequencing}

The purity, concentration, and integrity of RNA were tested using Nanodrop2000 (Thermo Fisher Scientific, Wilmington, DE). High-quality RNA was used to construct the cDNA library. The q-PCR method was used to accurately quantify the effective concentration ( $>2 \mathrm{nM}$ ) of the library. Transcriptome sequencing was performed on the Illumina platform with three biological replicates for each sample.

\section{Bioinformatics Analysis}

The clean reads were obtained from the original reads through quality control. The clean reads were compared with the genome sequence of the cultivated peanut Tifrunner to get the mapped reads. ${ }^{1}$ After quantitative gene analysis, differentially expressed genes (DEGs) were screened for functional annotation and enrichment analysis. The amount of gene expression used fragment per kilobase million (FPKM) to indicate the level of gene expression. Fold change $\geq 2$ and FDR $<0.01$ were used as the screening criteria. Raw sequencing data have been uploaded

\footnotetext{
${ }^{1}$ http://peanutbase.org/
} 
in the NCBI Gene Expression Omnibus under the accession number PRJNA PRJNA753947. ${ }^{2}$

\section{Determination of Jasmonic Acid, Abscisic Acid, Salicylic Acid, and Indole Acetic Acid Contents}

Fresh peanut leaves $(100 \mathrm{mg})$ were extracted with acetonitrile and centrifuged at $4^{\circ} \mathrm{C}$ at $12,000 \mathrm{rpm}$ for $10 \mathrm{~min}$ and then used for LCMS analysis (Vanquish, Thermo, United States). Waters HSS T3 $(50 \mathrm{~mm} \times 2.1 \mathrm{~mm}, 1.8 \mu \mathrm{m})$ liquid chromatography column, in which the injection volume was $2 \mu \mathrm{l}$ and the column temperature was $40^{\circ} \mathrm{C}$, with mobile phase $\mathrm{A}(0.1 \%$ acetic acid/acetonitrile) and mobile phase B (0.1\% acetic acid/water) was used. The optimized mass spectrometry analysis conditions were as follows: sheath gas 40 , auxiliary gas 10 , ion spray voltage $-2,800 \mathrm{~V}$, temperature $350^{\circ} \mathrm{C}$, and ion transfer tube temperature $320^{\circ} \mathrm{C}$.

\section{Quantitative Real-Time PCR}

The TRIZOL method was used to extract total RNA and further synthesize cDNA (TaKaRa, Beijing, China). Based on the representative sequence of the sequence library required for sequencing, Primar5.0 was used to design qPCR primers (Supplementary Table 1). The peanut actin gene was used as the internal reference gene. There were three statistical replicates for each gene. The $\Delta \Delta \mathrm{Ct}$ analysis was used for gene expression analysis. The $2^{-\Delta \Delta \mathrm{Ct}}$ method was used to calculate the amount of gene expression.

\section{Statistical Analysis}

The treatments were arranged in a completely randomized design (CRD). SPSS Statistics 20.0 (IBM, Chicago, United States) was used for one-way analysis of variance, and the Tukey's test at the $5 \%$ significance level was used to determine the difference among the treatments.

\section{RESULTS}

\section{Ultrasonic Treatment-Induced \\ Modulations in Morphological Traits and Aluminum Contents}

Ultrasonic treatment substantially improved the plant height and main root length in peanuts under $\mathrm{Al}$ stress. Compared with $\mathrm{CK}$, the plant height and main root length were increased by 2.31-and 1.6-fold, respectively, under US treatment in peanuts. Moreover, the $\mathrm{Al}$ contents were decreased by 53.07 and $18.8 \%$ in leaves and roots under US treatment than CK (Figures 2A-C).

\section{Ultrasonic Treatment Regulated the Expression of ALMT9 and FRDL1}

Compared with $\mathrm{CK}$, the expression of ALMT9 and FRDL1was increased by 222.9 and $132.1 \%$ under US treatment (Figures 3A,B).

${ }^{2}$ http://www.ncbi.nlm.nih.gov/geo

\section{Sequencing Quality Analysis}

Transcriptome sequencing of CK and US of "Guihua58" showed clean reads between 19383803 and 23820080. The GC content was between 44.7 and 45.1\%, whereas Q30 was greater than 92.22\%. Mapped reads were noted between 93.65 and $95.05 \%$. Uniq Mapped reads were noted between 85.34 and $86.39 \%$, while multiple mapped reads were noted between 8.31 and $8.8 \%$ (Table 1).

\section{Differentially Expressed Genes and Pathway Analysis}

Compared with CK, US treatment had 1,667 DEGs, of which 455 were upregulated and 1,212 were downregulated (Figure 4A). The volcano plot showed the similarity of gene expression and DEGs in CK vs. US (Figure 4B). The kyoto encyclopedia of genes and genomes (KEGG) enrichment analysis showed that 55 DEGs (66\% of all genes) were annotated into the KEGG pathway, and among them, 123 DEGs were significantly enriched (Figure 5). Among the up-annotated genes, the significantly enriched KEGG pathways were "peroxisome" and "plant hormone signal transduction." Among the downannotated genes, the significantly enriched KEGG pathways were "endocytosis" and "plant hormone signal transduction."

\section{The Effect of Ultrasonic Treatment on Salicylic Acid, Abscisic Acid, Indole Acetic Acid, and Jasmonic Acid Contents}

Compared with $\mathrm{CK}$, the SA and ABA contents were increased by 913.08 and $202.91 \%$ under US treatment (Figures 6A,B). In contrast, the JA and IAA contents were decreased by 33.25 and $53.06 \%$ under US treatment, as compared with CK (Figures 6C,D).

\section{The Effect of Ultrasonic Treatment on Transcription Factors}

Ultrasonic treatment affects the gene expression of TFs. The key TFs associated with US treatment in peanuts are exhibited in Figure 5. Among them, AP2 (28), bHLH (17), WRKY (11), MYB (8), and NAC (4) were differently expressed in both treatments (Figure 7A), where $15 \mathrm{TF}$ genes were selected for qRT-PCR verification. The gene expression level was consistent with the trend of the FPKM value, indicating that the transcriptome data were reliable (Figure 7B). The PCA and PLS-DA showed that NAC had the greatest regulatory effect on the ALMT9 and FRDL1 in US treatment (Figures 7C,D).

\section{DISCUSSION}

In previous studies, US treatment could trigger the antioxidant defense mechanism, such as increasing the activity of POD, catalase (CAT), ascorbate peroxidase (APX), and glutathione (GSH) contents (Huang et al., 2021). US treatment could produce irreversible changes in plant cells, such as the enlargement of microchannels and intercellular spaces, and improve the activity of biologically active hydrolysates, including plant primary 


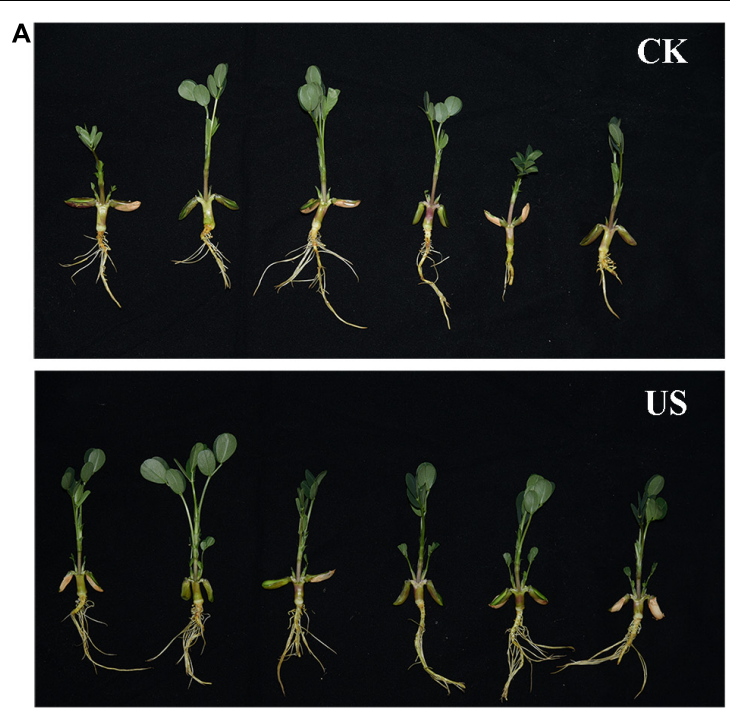

C

B Determination of $\mathrm{Al}$ concentration

\begin{tabular}{cc}
\hline Treatment & $\mathrm{Al}$ content $\left(\mu \mathrm{g} \mathrm{g}^{-1} \mathrm{DW}\right)$ \\
\hline CK-R & $856.2 \mathrm{a}$ \\
US-R & $695.2 \mathrm{~b}$ \\
CK-L & $268.3 \mathrm{a}$ \\
US-L & $125.9 \mathrm{~b}$ \\
\hline
\end{tabular}

R: roots; L: leaves
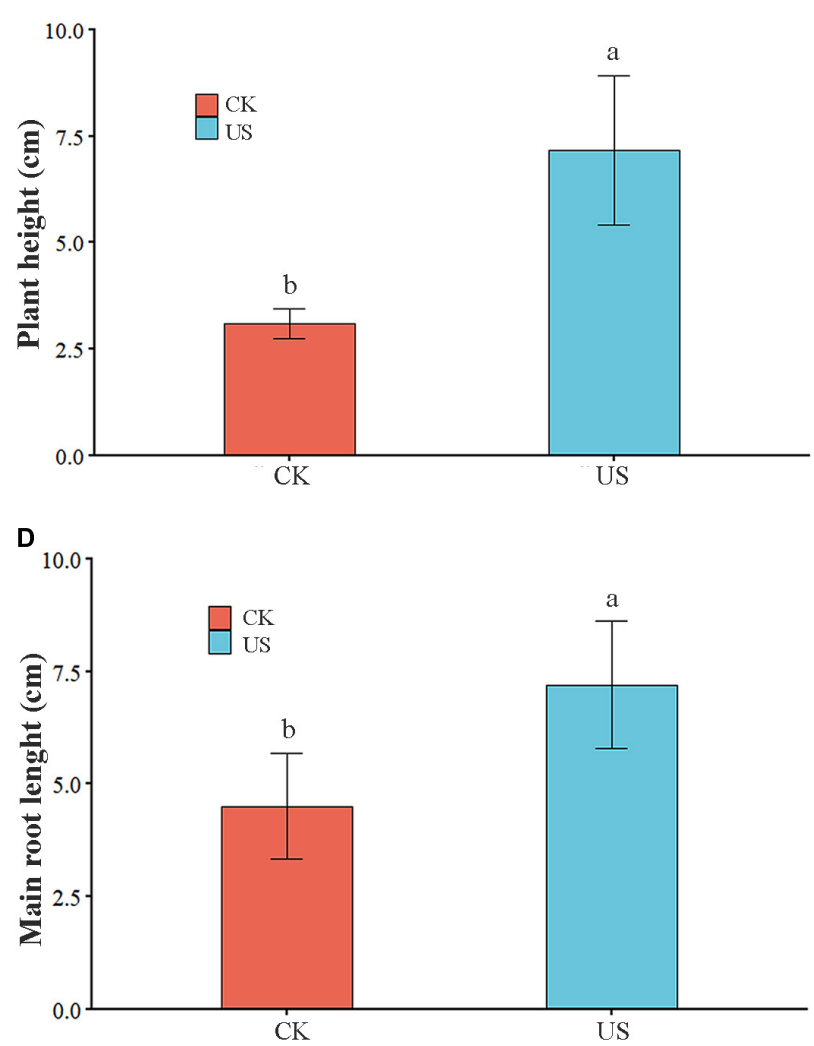

FIGURE 2 | Ultrasonic (US) treatment improved Al resistance in peanut. (A) Photography was performed after 5 days of Al treatment at room temperature. (B) Zn contents in leaves and grains in fragrant rice. Plant height (C) and main root length (D) were measured after 5 days of Al treatment at room temperature. Marking the same letters means $P \geq 0.05$ (LSD), and there is no significant difference; the difference between different letters means $P<0.05$ (LSD), and the difference is significant.
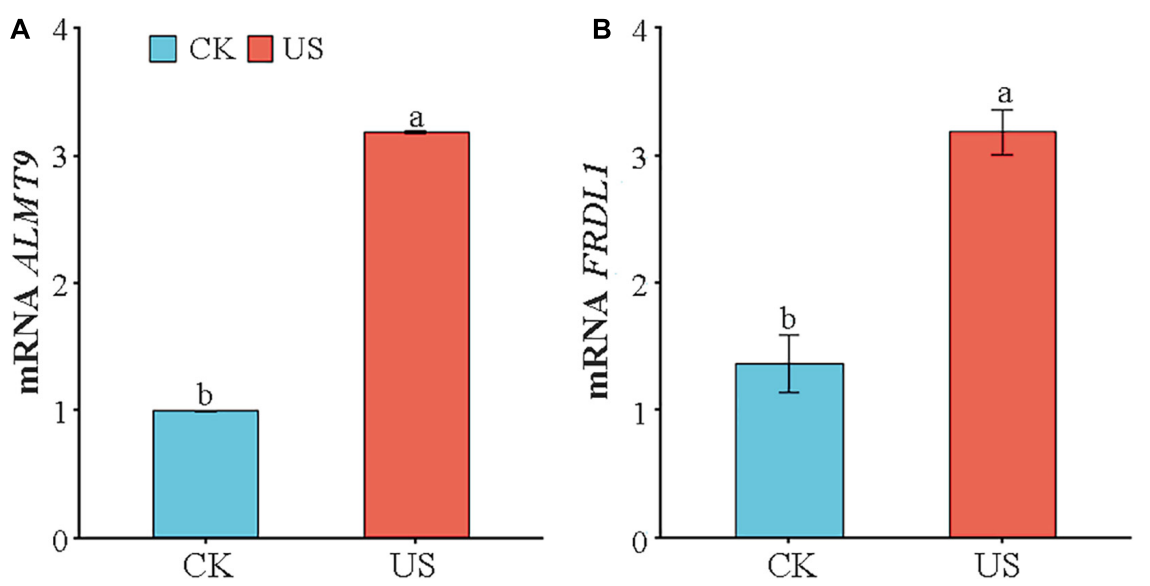

FIGURE 3 | Analysis of transcript levels of (A) ALMT9 and (B) FRDL1. Marking the same letters means $P \geq 0.05$ (LSD), and there is no significant difference; the difference between different letters means $P<0.05$ (LSD), and the difference is significant.

and secondary metabolites (Rajewska and Mierzwa, 2017). For example, US treatment could increase gamma-aminobutyric acid (GABA) content in rice, and GABA content was closely related to stress (Ding et al., 2018a). US treatment caused the temperature to rise, and the enzyme activity increased with the increase in temperature, and the invocation of enzymes was conducive to 
TABLE 1 | Statistics of raw sequencing data results.

\begin{tabular}{|c|c|c|c|c|c|c|}
\hline & Clean reads & GC content & $\% \geq Q 30$ & Mapped reads & Uniq mapped reads & Multiple map reads \\
\hline CK-1 & $2,38,20,080$ & $45.04 \%$ & $92.92 \%$ & 45,201,903 (94.88\%) & 41,009,840 (86.08\%) & 4,192,063 (8.80\%) \\
\hline CK-2 & $2,03,63,133$ & $44.88 \%$ & $92.57 \%$ & 38,700,086 (95.02\%) & 35,306,767 (86.69\%) & 3,393,319 (8.33\%) \\
\hline CK-3 & $1,94,06,816$ & $44.93 \%$ & $92.93 \%$ & $36,893,310$ (95.05\%) & 33,610,053 (86.59\%) & $3,283,257(8.46 \%)$ \\
\hline US-1 & $1,93,83,803$ & $45.10 \%$ & $92.45 \%$ & $36,643,216$ (94.52\%) & 33,333,320 (85.98\%) & $3,309,896$ (8.54\%) \\
\hline US-2 & $2,11,41,555$ & $44.70 \%$ & $92.31 \%$ & $39,598,744$ (93.65\%) & $36,084,199$ (85.34\%) & $3,514,545$ (8.31\%) \\
\hline US-3 & $2,03,92,853$ & $44.98 \%$ & $92.22 \%$ & 38,208,017 (93.68\%) & $34,804,622$ (85.34\%) & 3,403,395 (8.34\%) \\
\hline
\end{tabular}
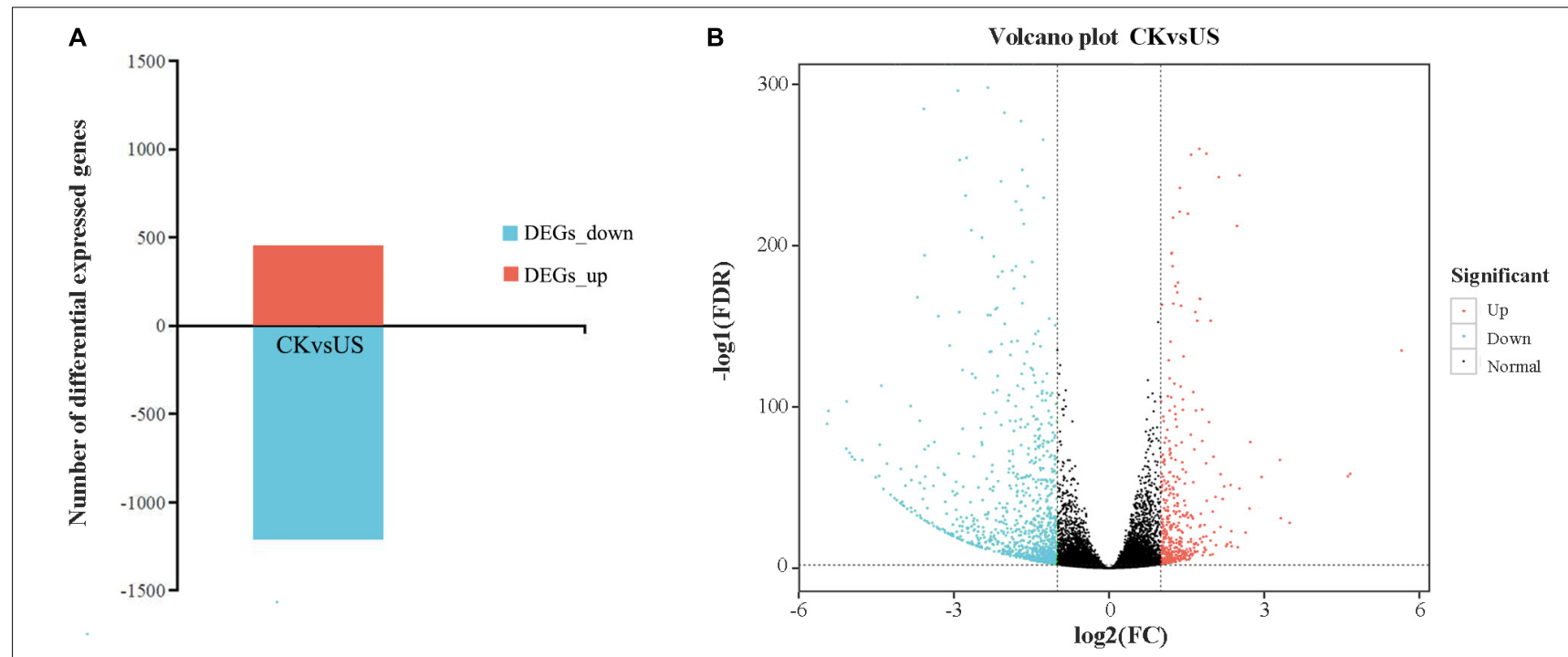

FIGURE 4 | Summary of differentially expressed genes (DEGs) and volcano plot analysis. (A) DEGs. (B) Volcano plot analysis. Red color indicates upregulated genes. Blue color indicates downregulated genes.

further growth and development (Ding et al., 2018a). Holes and cracks were found in the surface microstructure of the germinated brown rice grains after US treatment (Ding et al., 2018b). Plants have developed exclusion and internal tolerance mechanisms for heavy metal stress tolerance (Ali et al., 2014, 2015; Mwamba et al., 2016, 2020). Similarly, Al tolerance mechanisms have been explained in Figure 1. Generally, the root tip was an initial part of a plant that came in contact at first with $\mathrm{Al}^{3+}$ in soil solution and/or $\mathrm{Al}$ contaminated growing medium (Shen and Yan, 2001). High concentrations of Al toxicity could cause obvious morphological and structural changes in peanut root tip cells, which were manifested by inhibiting root elongation and causing programmed cell death (Zhan et al., 2008), such as Panax ginseng (Farh et al., 2017), Zea mays (Kidd et al., 2001), Triticum aestivum (Ma and She, 2006), Allium cepa (Achary et al., 2012), Camellia sinensis (Qu et al., 2021), Glycine max (Dos et al., 2018), Oryza sativa L. (Liu S. et al., 2016), Arabidopsis (Degenhardt et al., 1998), and Citrus sinensis (Yang et al., 2021). $\mathrm{Al}^{3+}$ entered the nucleus of wheat root cells to condense chromatin or bind DNA molecules, causing DNA damage in the rhizosphere (Ma and She, 2006). Al induced ROS to promote oxidative burst, causing cell death and DNA damage in A. cepa (Achary et al., 2012). Al stress significantly inhibited the growth of tea seedlings by reducing chlorophyll synthesis and reducing photosynthetic efficiency ( $\mathrm{Qu}$ et al., 2021). After Al treatment, Al-tolerant corn cultivars not only secrete citric acid but also secrete a mixture of phenols including catechol, catechin, and bark to chelate Al, thereby improving the Al tolerance of corn (Kidd et al., 2001). However, there were relatively few studies on how to improve the Al tolerance mechanism of peanuts. In this study, it was found that US treatment substantially improved the plant height and main root length in peanuts under $\mathrm{Al}$ stress. Moreover, the $\mathrm{Al}$ contents were found to be decreased in roots and leaves under US treatment than CK (Figure 2). A large number of studies had found that US treatment mainly stimulates the internal material properties and physiological activities of plants through vibration. For example, it could promote the oxidation, reduction, decomposition, and synthesis of the internal substances of plant cells. By increasing the germination rate and germination potential of seeds, the yield and quality of crops could be improved (Fu et al., 2020).

The two transporter families MATE and ALMT play an essential role in improving the resistance to metal toxicity, counterion stability, and promoting the absorption of mineral elements in crops (Omote et al., 2006; Sharma et al., 2016). Through heterologous expression in Xenopus oocytes, it was found that the MATE gene in tobacco, wheat, and barley could promote citric acid efflux and enhance its Al tolerance 

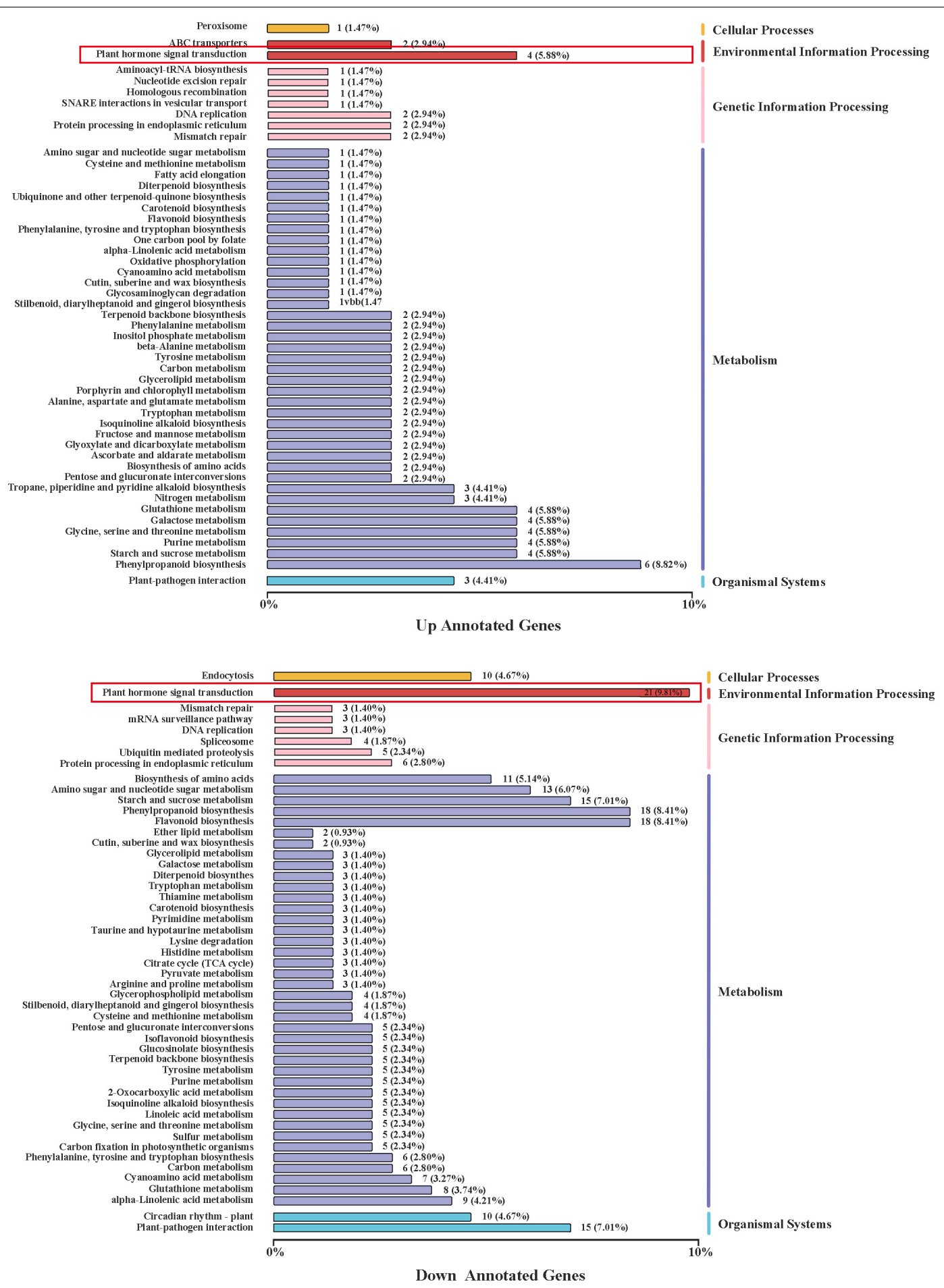

FIGURE 5 | Regulations of the KEGG pathway.

(Furukawa et al., 2007). ALMT encoded a malate transporter while also performing other important functions, such as maintaining the balance of malate and participating in cell osmotic regulation (Kochian et al., 2015). ZmALMT1 was found to be involved in ion-selective transport in maize root tips
(Sharma et al., 2016); HvALMT1 was involved in the regulation of stomata opening and closing and root growth and development in barley (Xu et al., 2015). The AhFRDL1 gene was cloned in peanuts, and the expression of the AhFRDL1 gene was upregulated to improve the tolerance of roots to $\mathrm{Al}$ stress 


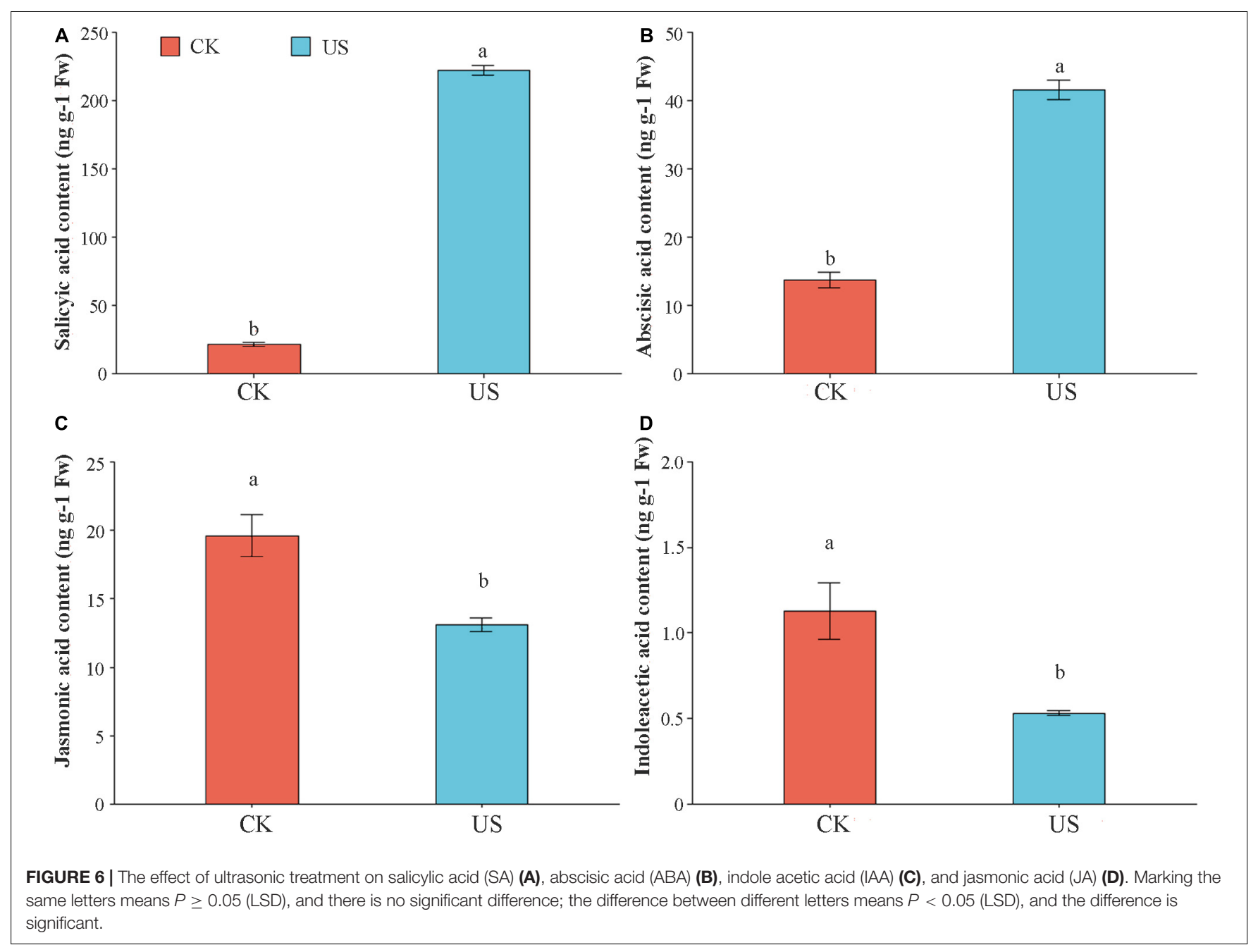

(Qiu et al., 2019). This study showed that the expression of the FRDL1 gene was also upregulated after ultrasound treatment (Figure 3B). Furthermore, it was found that Al-tolerant cultivars of wheat (T. aestivum L.), soybean (G. max), and Arabidopsis (Arabidopsis thaliana) had higher ALMT gene expression than the sensitive cultivars (Liang et al., 2013). We have also found that the expression of the ALMT9 gene was significantly upregulated under US treatment (Figure 3A), indicating that US treatment could increase the expression of the FRDL1 and ALMT9 genes to increase the external $\mathrm{Al}$ excretion mechanism of peanut.

Transcriptome analysis revealed that KEGG enrichment analysis showed that the DEGs of plant hormone signal transduction were significantly enriched (Figure 5). Plant hormones play an important role in the $\mathrm{Al}$ tolerance of crops. For instance, the SA induced the $\mathrm{Al}$ stress tolerance by inducing plant systemic resistance (SAR), cellular antioxidant mechanisms, and photosynthesis (Wang et al., 2016). Under Al stress, the accumulation of endogenous ABA content in soybeans played an essential role in Al tolerance (Hou et al., 2010). This study found that the SA and ABA contents were significantly upregulated after US treatment, indicating that US treatment could promote the perception stage of hormones and the signal transmission stage to promote their synthesis (Figure 6B). The endogenous JA in corn played an important role in the drought resistance response. The lack of endogenous JA could reduce water loss and improve the survival ability under drought conditions (Wang $\mathrm{H}$. Y. et al., 2019). In this study, it was found that the JA content was also significantly reduced under US treatment (Figure 6C). Cytokinin and IAA participated in the regulation of the response process against $\mathrm{Al}$ stress synergistically ( $\mathrm{He}$ et al., 2012). The interaction between IAA and cytokinin under $\mathrm{Al}$ stress was mainly linked by auxin-responsive transcription factor (ARF). Under Al or metal stress, ARF7 mediated the stalk between IAA and cytokinin and promoted the synthesis of isopentenyl transferases (IPT). The IPT-dependent cytokinin acted on the downstream of ARF7-mediated auxin signal and synergistically regulated the inhibition of root growth (Yang et al., 2017). However, this study found that IAA content was downregulated under US treatment (Figure 6D), which may be related to the regulation of IAA and cytokinin in a synergistic manner.

In addition, four main types of TFs were involved in the regulation of $\mathrm{Al}$ tolerance in peanuts. First, the expression of 

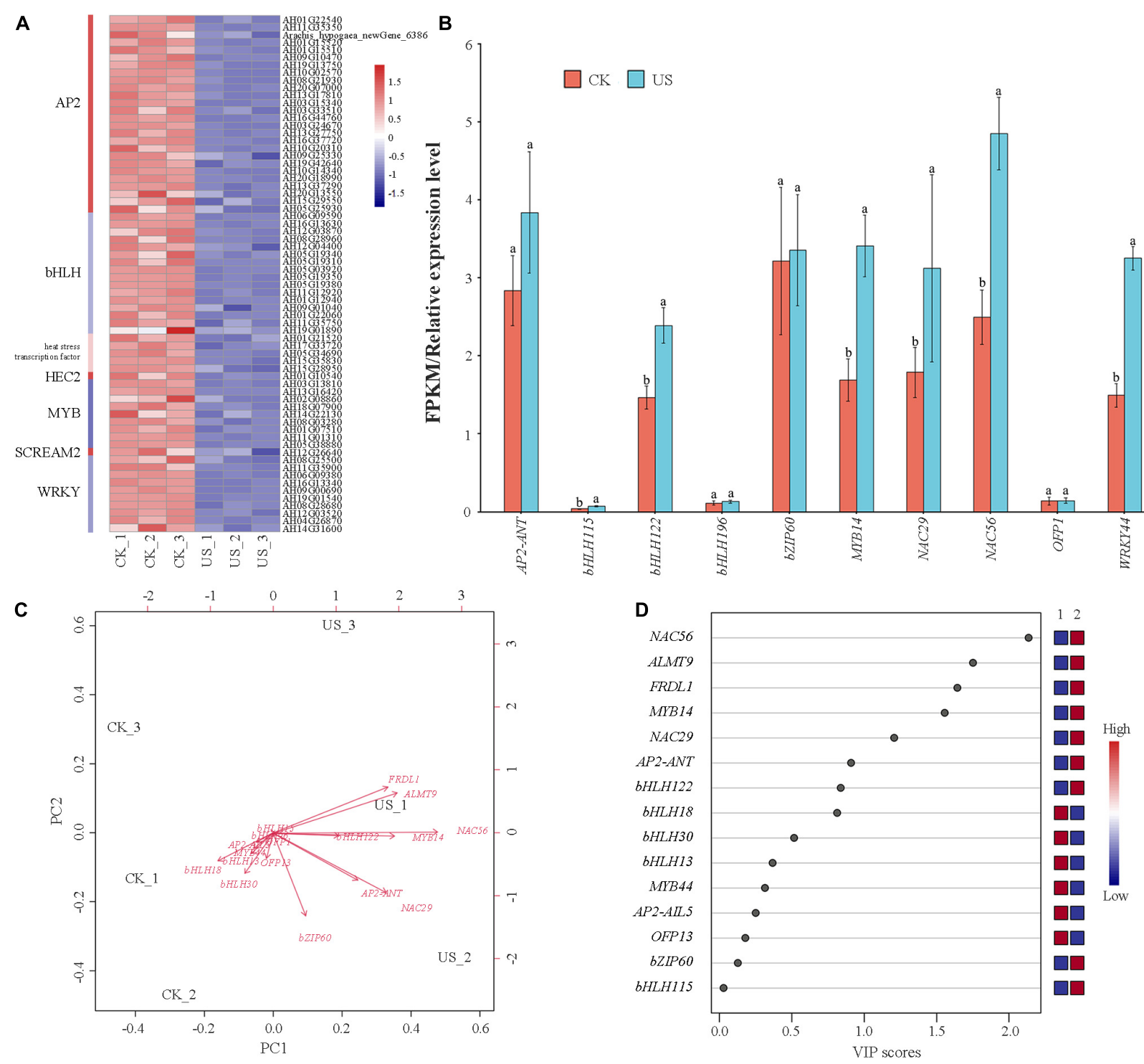

FIGURE 7 | Heatmap of known 33 transcription factors (TFs). (A) Red color indicates downregulation, and blue color indicates upregulation. (B) Comparison of the FPKM value obtained using RNA-seq analysis with the gene expression obtained using quantitative real-time (qRT)-PCR analysis. (C) Principal component analysis (PCA). (D) Partial least squares discriminant analysis (PLS-DA).

Al-tolerant genes increased with the copy number of genes in the genome (Daspute et al., 2017). Second, the transposon insertion at the front end of the Al-tolerant gene, i.e., insertion of the transposon could be used as the promoter of the subsequent gene and enhanced the expression of the subsequent gene (Ferreira et al., 2017). Third, the tandem repeats in the promoter region enhanced the expression level of resistance genes (Ryan et al., 2010). The expression level of the fourth resistance gene was related to the number of cis-acting elements of the TF ART1 (Chen Z. C. et al., 2013). In Arabidopsis, AtSTOP1 could regulate the expression of downstream Altolerant genes, but it was not affected by $\mathrm{Al}$ stress at the transcription level. Studies have shown that AtSTOP1 was regulated by the F-box protein RAE1 (AL-activated malate transporter expression 1) after transcription. RAE1 regulated the stability of AtSTOP1 through the ubiquitin/26S proteasome pathway (Zhang Y. et al., 2019). Guo et al. (2020) showed that hyperrecombination protein 1 (HPR1) regulated the output of nuclear-cytoplasmic STOP1 mRNA, thereby regulating the expression of genes downstream of STOP1. Fang et al. (2020) showed that the SUMO of STOP1 was involved in the regulation of Al tolerance. In rice, the homologous protein OsART1 participated in rice $\mathrm{Al}$ tolerance by regulating the expression of downstream Al-tolerant genes (Yamaji et al., 2009). Members of the WRKY family-involved Al stress response have been found in both Arabidopsis and rice. In Arabidopsis, WRKY46 was a transcriptional repressor. It promoted the expression of AtALMT1 through the downregulation of its expression level, 
increased root tip malic acid secretion, and ultimately improved the Al tolerance of Arabidopsis (Ding et al., 2013). Recently, Li C. X. et al. (2020) identified another member of the WRKY family, AtWRKY47, which modulated the distribution of $\mathrm{Al}$ between apoplasts and symplasts by regulating genes related to cell wall modification, thereby increasing the Al tolerance of Arabidopsis. Lou et al. (2019) found that the NAC family was involved in the Al tolerance of Vigna unguiculata. This study found that the gene expression of many TFs was upregulated under US treatment (Figure 7A), and the expression of ALMT9 and FRDL1 genes were also upregulated. This may be due to the effect of US treatment on TFs related to the further regulation of gene expression; however, the mode through which TFs regulate gene expression requires further research. We speculated that US treatment may improve the external rejection mechanism and internal tolerance mechanism of peanuts by regulating the antioxidant defense system, enzyme activity, hormones, and TFs. Ultrasonic treatment, as a pollution-free physical treatment technology, had the value of popularization and application.

\section{CONCLUSION}

Ultrasonic treatment improved the morphological traits of peanuts under $\mathrm{Al}$ stress. US seed treatment regulates the expression of internal hormones, namely, SA, ABA, IAA, and JA, and TFs, which further regulate gene expression (ALMT9 and FRDL1) to improve the Al tolerance in peanuts. There is no doubt that the US seed treatment induced the Al tolerance in peanuts, but it is necessary to optimize the seed treatment time and frequency for different peanut cultivars and further experiments in the field are required.

\section{REFERENCES}

Achary, V. M. M., Parinandi, N. L., and Panda, B. B. (2012). Aluminum induces oxidative burst, cell wall NADH peroxidase activity, and DNA damage in root cells of Allium cepa L. Environ. Mol. Mutagen. 53, 550-560. doi: 10.1002/em. 21719

Ali, B., Gill, R. A., Yang, S., Gill, M. B., Ail, S., Rafiq, M. T., et al. (2014). Hydrogen sulfide alleviates cadmium-induced morpho-physiological and ultrastructural changes in Brassica napus. Ecotoxicol. Environ. Saf. 110, 197-207. doi: 10.1016/ j.ecoenv.2014.08.027

Ali, B., Gill, R. A., Yang, S., Gill, M. B., Farooq, M. A., Liu, D., et al. (2015). Up-regulation of cadmium-induced proteomic and metabolic changes by 5 aminolevulinic acid in leaves of Brassica napus L. PLoS One 10:0123328. doi: 10.1371/journal.pone.0123328

Ali, B., Tao, Q. J., Zhou, Y. F., Gill, R. A., Ali, S., Rafiq, M. T., et al. (2013a). 5-Aminolevolinic acid mitigates the cadmium-induced changes in Brassica napus as revealed by the biochemical and ultra-structural evaluation of roots. Ecotoxicol. Environ. Saf. 92, 271-280. doi: 10.1016/j.ecoenv.2013.02.006

Ali, B., Wang, B., Ali, S., Ghani, M. A., Hayat, M. T., Yang, C., et al. (2013b). 5-Aminolevulinic acid ameliorates the growth, photosynthetic gas exchange capacity and ultrastructural changes under cadmium stress in Brassica napus L. J. Plant Growth Regul. 32, 604-614. doi: 10.1007/s00344-0139328-6

Ashraf, U., Kanu, A. S., Deng, Q. Q., Mo, Z. W., Pan, S. G., Tian, H., et al. (2017). Lead $(\mathrm{Pb})$ toxicity; physio-biochemical mechanisms, grain yield, quality, and $\mathrm{Pb}$ distribution proportions in scented rice. Front. Plant Sci. 28:259. doi: 10.3389/fpls.2017.00259

\section{DATA AVAILABILITY STATEMENT}

The original contributions presented in the study are publicly available. This data can be found here: https://www.ncbi.nlm.nih. gov/bioproject/PRJNA753947.

\section{AUTHOR CONTRIBUTIONS}

$\mathrm{YZ}, \mathrm{GB}$, and XW designed the experiment. GB, QZ, SL, SH, $\mathrm{AM}$, and $\mathrm{ZC}$ performed the experiment, data collection, lab analysis, and data analysis. QZ, SL, and $\mathrm{SH}$ contributed in providing chemicals, reagent, analyses, and tools. GB and QZ prepared the initial draft. GB and UA finalized the initial draft. XW was fully responsible for the distribution of all materials associated with this manuscript. All authors read and approved the final manuscript.

\section{FUNDING}

This study was supported by the Natural Science Foundation of China (31770652 and 32071737) and the grant (202002010010) from Guangzhou Key Laboratory for Research and Development of Crop Germplasm Resources.

\section{SUPPLEMENTARY MATERIAL}

The Supplementary Material for this article can be found online at: https://www.frontiersin.org/articles/10.3389/fpls.2021. 807021/full\#supplementary-material

Bao, G. G., Ashraf, U., Wan, X. R., Zhou, Q., Li, S. Y., Wang, C., et al. (2021). Transcriptomic analysis provides insights into foliar zinc application induced up-regulation in 2-Acetyl-1-pyrroline and related transcriptional regulatory mechanism in fragrant rice. J. Agric. Food Chem. 69, 11350-11360. doi: 10.1021/ acs.jafc.1c03655

Chapman, J. M., Muhlemann, J. K., Gayomba, S. R., and Muday, G. K. (2019). RBOH-dependent ROS synthesis and ROS scavenging by plant specialized metabolites to modulate plant development and stress responses. Chem. Res. Toxicol. 32, 370-396. doi: 10.1021/acs.chemrestox.9b00028

Chauhan, D. K., Yadav, V., Vaculík, M., Gassmann, W., Pike, S., Arif, N., et al. (2021). Aluminum toxicity and aluminum stress-induced physiological tolerance responses in higher plants. Crit. Rev. Biotechnol. 41, 715-730. doi: 10.1080/07388551.2021.1874282

Chen, Y. P., Liu, Q., Yue, X. Z., Meng, Z. W., and Liang, J. (2013). Ultrasonic vibration seeds showed improved resistance to cadmium and lead in wheat seedling. Environ. Sci. Pollut. Res. 20, 4807-4876. doi: 10.1007/s11356-0121411-1

Chen, Z. C., Yokosho, K., Kashino, M., Zhao, F. J., Yamaji, N., and Ma, J. F. (2013). Adaptation to acidic soil is achieved by increased numbers of cis-acting elements regulating ALMT1 expression in Holcus lanatus. Plant J. 76, 10-23. doi: $10.1111 /$ tpj.12266

Dai, B. J., Chen, C., Liu, Y., Liu, L. J., Qaseem, M. F., Wang, J. X., et al. (2020). Physiological, biochemical, and transcriptomic responses of neolamarckia cadamba to aluminum stress. Int. J. Mol. Sci. 21, 9624-9652. doi: 10.3390/ ijms 21249624

Daspute, A. A., Sadhukhan, A., Tokizawa, M., Yuriko, K., Panda, S. K., and Hiroyuki, K. (2017). Transcriptional regulation of aluminum-tolerance genes 
in higher plants: clarifying the underlying molecular mechanisms. Front.Plant Sci. 8:1358. doi: 10.3389/fpls.2017.01358

Degenhardt, J., Larsen, P. B., Howell, S. H., and Kochian, L. V. (1998). Aluminum resistance in the Arabidopsis mutant alr-104 is caused by an aluminum-induced increase in rhizosphere pH. Plant Physiol. 117, 19-27. doi: 10.1104/pp.117.1.19

Ding, J. Z., Ulanov, A., Dong, M. Y., Yang, T. W., Nemzer, B. V., Xiong, S. B., et al. (2018a). Enhancement of gama-aminobutyric acid (GABA) and other healthrelated metabolites in germinated red rice (Oryza sativa L.) by ultrasonication. Ultrasonics Sonochem. 40, 791-797. doi: 10.1016/j.ultsonch.2017.08.029

Ding, J. Z., Hou, G. G., Dong, M., Xiong, S., Zhao, S., and Feng, H. (2018b). Physicochemical properties of germinated dehulled rice flour and energy requirement in germination as affected by ultrasound treatment. Ultrasonics Sonochem. 41, 484-491. doi: 10.1016/j.ultsonch.2017.10.010

Ding, Z. J., Yan, J. Y., Xu, X. Y., Li, G. X., and Zheng, S. J. (2013). WRKY46 functions as a transcriptional repressor of $A L M T 1$, regulating aluminum-induced malate secretion in Arabidopsis. Plant J. 76, 825-835. doi: 10.1111/tpj.12337

Dos, R., Manzani, L., Gestal, R., Queiroz, B., Ferreira, S. E., Kondo, S., et al. (2018). Depicting the physiological and ultrastructural responses of soybean plants to Al stress conditions. Plant Physiol. Biochem. 130, 377-390. doi: 10.1016/j. plaphy.2018.07.028

Fang, Q., Zhang, J., Zhang, Y., Fan, N., Burg, H. A., and Huang, C. F. (2020). Regulation of aluminum resistance in Arabidopsis involves the SUMOylation of the zinc finger transcription factor STOP1. Plant Cell 32, 3921-3938. doi: $10.1105 /$ tpc. 20.00687

Farh, E. A., Kim, Y. J., Sukweenadhi, J., Singh, P., and Yang, D. C. (2017). Aluminium resistant, plant growth-promoting bacteria induce over expression of aluminium stress related genes in Arabidopsis thaliana and increase the ginseng tolerance against aluminium stress. Microbiol. Res. 200, 45-52. doi: 10.1016/j.micres.2017.04.004

Ferreira, J. R., Faria, B. F., Junior, M. C., Delatorre, C. A., Minella, E., and Pereira, J. F. (2017). Is a non-synonymous SNP in the HvAACT1 coding region associated with acidic soil tolerance in barley? Genet. Mol. Biol. 40, 480-490. doi: 10.1590/1678-4685-GMB-2016-0225

Fu, Y. Q., Liu, Y. Z., Liang, K. M., Yan, Z. S., Zhong, X. H., Huang, N. R., et al. (2020). Effect of ultrasonic seed treatment on grain yield and quality of double-cropping late rice in south China. J. Agric. 10, 1-4.

Furukawa, J., Yamaji, N., Wang, H., Mitani, N., Murata, Y., Sato, K., et al. (2007). An Aluminum-activated citrate transporter in barley. Plant Cell Physiol. 48, 1081-1091. doi: 10.1093/pcp/pcm091

Ge, W. J., and Ren, W. D. (2019). Summary of ultrasonic treatment of rice seeds in Qianjin farm. Friends Far. Rich 12, 143-144.

Godon, C., Mercier, C., Wang, X. Y., David, P., Richaud, P., Nussaume, L., et al. (2019). Under phosphate starvation condition. Fe and Al trigger the transcription factor STOP1 to accumulate in the nucleus of Arabidopsis root cells. Plant J. Cell Mol. Biol. 99, 937-949. doi: 10.1111/tpj.14374

Guo, J. L., Zhang, Y., Gao, H. L., Li, S. B., Wang, Z. Y., and Huang, C. F. (2020). Mutation of HPR1 encoding a component of the THO/TREX complex reduces STOP1 accumulation and aluminum resistance in Arabidopsis thaliana. New Phytologist 228, 179-193. doi: 10.1111/nph.16658

Guo, K. T. (2016). Effects of ultrasonic wave on seed viability and physiological characteristics of lupin seeds. Hubei Agric. Sci. 55, 5282-5285.

Han, T. F., Liu, K. L., Huang, J., Ma, C. B., Zheng, L., Wang, H. Y., et al. (2020). Spatio-temporal evolution of soil $\mathrm{pH}$ and its driving factors in the main Chinese farmland during past 30 years. Plant Nutr. Fertil. Sci. 26, 2137-2149.

He, H. Y., He, L., and Gu, M. H. (2012). Interactions between nitric oxide and plant hormones in aluminum tolerance. Plant Signal. Behav. 7, 469-471. doi: $10.4161 /$ psb. 19312

Hou, N. N., You, J. F., Pang, J. D., Xu, M. Y., Chen, G., and Yang, Z. M. (2010). The accumulation and transport of abscisic acid insoybean (Glycine max L.) under aluminum stress. Plant Soil 330, 127-137. doi: 10.1007/s11104-009-0184-x

Huang, S. H., Rao, G. S., Ashraf, U., Deng, Q. Q., Dong, H., Zhang, H. L., et al. (2021). Ultrasonic seed treatment improved morpho-physiological and yield traits and reduced grain $\mathrm{Cd}$ concentrations in rice. Ecotoxicol. Environ. Saf. 214:112119. doi: 10.1016/j.ecoenv.2021.112119

Kidd, P. S., Llugany, M., Poschenrieder, C., Gunsé, B., and Barceló, J. (2001). The role of root exudates in aluminium resistance and silicon-induced amelioration of aluminium toxicity in three varieties of maize (Zea mays L.). J. Exp. Bot. 52, 1339-1352. doi: 10.1093/jxb/52.359.1339
Kochian, L. V., Piñeros, M. A., Liu, J. P., and Magalhaes, J. V. (2015). Plant adaptation to acid soils: the molecular basis for crop aluminum resistance. Annu. Rev. Plant Biol. 66, 571-598. doi: 10.1146/annurev-arplant-043014114822

Li, A. T. (2019). Improved Configuration Test And Application Study On Infiltration Storage And Water Quality Treatment Performance Of Typical Soils In South China, Master's thesis. Guangdong: Guangdong University of Technology.

Li, C. X., Yan, J. Y., Ren, J. Y., Sun, L., Xu, C., Li, G. X., et al. (2020). A WRKY transcription factor confers aluminum tolerance via regulation of cell wall modifying genes. J. Intergr. Plant Biol. 62, 1176-1192. doi: 10.1111/jipb.12888

Li, C., Yan, J., Ren, J., Sun, L., Xu, C., Li, G., et al. (2020). A WRKY transcription factor confers aluminum tolerance via regulation of cell wall modifying genes. J. Integr. Plant Biol. 8, 1176-1192.

Li, J. C., Lin, Z., and Lin, H. M. (2013). Research on the land degradation status and prevention countermeasures in south China. J. Anhui Agric. Sci. 41:418.

Liang, C. Y., Piñeros, M. A., Tian, J., Yao, Z. F., Sun, L. L., Liu, J. P., et al. (2013). Low $\mathrm{pH}$, aluminum, and phosphorus coordinately regulate malate exudation through GmALMT1 to improve soybean adaptation to acid soils. Plant Physiol. 161, 1347-1361. doi: 10.1104/pp.112.208934

Liu, F., Zhang, Z., and Wang, J. (2020). Research Progress on planting and application technology of high oleic acid peanut in China. Chin. J. Oil Crop Sci. $184,34-37$.

Liu, J., Wang, Q. Z., Karagić, Đ, Liu, X., Cui, J., Gui, J., et al. (2016). Effects of ultrasonication on increased germination and improved seedling growth of aged grass seeds of tall fescue and Russian wildrye. Sci. Rep. 6:22403. doi: $10.1038 /$ srep 22403

Liu, S., Gao, H. L., Wu, X. Y., Fang, Q., Chen, L., Zhao, F. J., et al. (2016). Isolation and characterization of an aluminum-resistant mutant in rice. Rice 9, 1-13. doi: 10.1186/s12284-016-0132-3

Liu, Y. M. (2018). Characteristics Of Root Exudates Of Pinus Massoniana In Aluminate Environment And Its Rhizosphere Effect On Alleviating Aluminum Toxicity, Doctoral's Thesis. Chongqing: Southwest University.

Lou, H. Q., Fan, W., Jin, J. F., Xu, J. M., Chen, W. W., Yang, J. L., et al. (2019). A NAC-type transcription factor confers aluminium resistance by regulating cell wall-associated receptor kinase 1 and cell wall pectin. Plant Cell Environ. 43, 463-478. doi: 10.1111/pce.13676

Ma, Y. L., and She, X. P. (2006). Effects and DNA damages of $\mathrm{Al}^{3+}$ and $\mathrm{Cd}^{2+}$ in wheat seedlings. Xibei Zhiwu Xuebao. 26, 729-735.

Mwamba, T. M., Islam, F., Ali, B., Lwalaba, J. L. W., Gill, R. A., Zhang, F., et al. (2020). Comparative metabolomic responses of low- and high-cadmium accumulating genotypes reveal the cadmium adaptive mechanism in Brassica napus. Chemosphere 250:126308. doi: 10.1016/j.chemosphere.2020.126308

Mwamba, T. M., Li, L., Gill, R. A., Islam, F., Nawaz, A., Ali, B., et al. (2016). Differential subcellular distribution and chemical forms of cadmium and copper in Brassica napus. Ecotoxicol. Environ. Saf. 134, 239-249. doi: 10.1016/j. ecoenv.2016.08.021

Omote, H., Hiasa, M., Matsumoto, T., Otsuka, M., and Moriyama, Y. (2006). The MATE proteins as fundamental transporters of metabolic and xenobiotic organic cations. Trends Pharmacol. Sci. 27, 578-593. doi: 10.1016/j.tips.2006. 09.001

Panda, S. K., Baluška, F., and Matsumoto, H. (2009). Aluminum stress signaling in plants. Plant Signal Behav. 4, 592-597. doi: 10.4161/psb.4.7.8903

Qiu, W., Wang, N. Q., Dai, J., Wang, T. Q., Kochian, L. V., Liu, J. P., et al. (2019). AhFRDL1 mediated citrate secretion contributes to adaptation of peanuts for Fe deficiency and Al stress. J. Exp. Bot. 70, 2873-2886. doi: 10.1093/jxb/erz089

Qu, X. J., Chen, M., Liao, J., Zhang, C. H., Chen, L. S., and Yuan, J. (2021). Physiological response of phosphorus alleviates aluminum stress in leaves of Camellia oleifera. J. Cent. South Univ. For. Technol. 41, 62-71.

Quimbaya, M., Gallo-Franco, J. J., Sosa, C. C., and Ghneim, T. (2020). Epigenetic control of plant response to heavy metal stress: a new view on aluminum tolerance. Front. Plant Sci. 11:602625. doi: 10.3389/fpls.2020.602625

Rahman, M. A., Lee, S. H., Ji, H. C., Kabir, A. H., Jones, C. S., and Lee, K. W. (2018). Molecular sciences importance of mineral nutrition for mitigating aluminum toxicity in plants on acidic soils: current status and opportunities. Int. J. Mol. Sci. 19, 3073-3101. doi: 10.3390/ijms19103073

Rajewska, K., and Mierzwa, D. (2017). Influence of ultrasound on the microstructure of plant tissue. Innov. Food Sci. Emerg. Technol. 43, 117-129. doi: 10.1016/j.ifset.2017.07.034 
Ranjan, A., Sinha, R., Lal, S. K., Bishi, S. K., and Singh, A. K. (2021). Phytohormone signalling and cross-talk to alleviate aluminium toxicity in plants. Plant Cell Rep. 40, 1331-1343. doi: 10.1007/s00299-021-02724-2

Rao, G. S., Ashraf, U., Huang, S. H., Cheng, S. R., Abrar, M., Mo, Z. W., et al. (2018). Ultrasonic seed treatment improved physiological and yield traits of rice under lead toxicity. Environ. Sci. Pollut. Res. Int. 25, 33637-33644. doi: 10.1007/s11356-018-3303-5

Rao, G. S., Huang, S. H., Ashraf, U., Mo, Z. W., Duan, M. Y., Pan, S. G., et al. (2019). Ultrasonic seed treatment improved cadmium (Cd) tolerance in Brassica napus L. Ecotoxicol. Environ. Saf. 185, 109659-109660. doi: 10.1016/j.ecoenv.2019. 109659

Ryan, P. R., Raman, H., Gupta, S., Sasaki, T., Yamamoto, Y., and Delhaize, E. (2010). The multiple origins of aluminum resistance in hexaploid wheat include Aegilops tauschii and more recent cis mutations to TaALMT1. Plant J. 64, 446-455. doi: 10.1111/j.1365-313X.2010.04 338.x

Sharma, T., Dreyer, I., Kochian, L., and Piñeros, M. (2016). The ALMT family of organicacid transporters in plants and their involvement in detoxificationand nutrient security. Front. Plant Sci. 7:1488. doi: 10.3389/fpls.2016. 01488

Shen, H., and Yan, X. L. (2001). Types of aluminum toxicity and plants resistance to aluminum toxicity. Chin. J. Soil Sci. 32, 281-285.

Shen, H., Ayalew, L., Mineo, Y., Hiroki, O., Koichi, S., Yan, X. L., et al. (2004). Effect of K-252a and abscisic acid on the efflux of citrate from soybean roots. J. Exp. Bot. 55, 663-671. doi: 10.1093/jxb/erh058

Singh, H., Bhat, J. A., Singh, V. P., Corpas, F. J., and Yadav, S. R. (2021). Auxin metabolic network regulates the plant response to metalloids stress. J. Hazard. Mater. 405:124250. doi: 10.1016/j.jhazmat.2020.124250

Singh, S., Tripathi, D. K., Singh, S., Sharma, S., Dubey, N. K., Chauhan, D. K., et al. (2017). Toxicity of aluminium on various levels of plant cells and organism. Environ. Exp. Bot. 137, 177-193.

Sun, L., Liu, L. P., Wang, J., Li, Q., He, R. H., and Ma, H. L. (2020). Effects of ultrasonic treatment on the germination and cellular morphology of antrodia camphorara arthrospores. J. Anhui Agric. Sci. 48:204.

Swarup, R., and Bhosale, R. (2019). Developmental roles of AUX1/LAX auxin infux carriers in plants. Front. Plant Sci. 10:1306. doi: 10.3389/fpls.2019.01306

Wang, B. Z., Zhang, Y. M., Zhang, J. L., Bi, S. Q., and Kong, H. (2016). Effects of salicylic acid on growth of Astragalus adsurgens seedlings under salt stress. Cao Ye Xue Bao 25, 74-80.

Wang, H. Y., Cheng, C., An, L. K., Qin, J., and Yan, Y. X. (2019). Endogenous JA regulates leaf photosynthesis and drought-tolerance response under drought condition in maize. Nanjing Nong Ye Da Xue Xue Bao 42, 30-38.

Wang, M., Qiao, J. Y., Yu, C. L., Chen, H., Sun, C. D., Huang, L. Z., et al. (2019). The auxin infux carrier. OsAUX3, regulates rice root development and responses to aluminium stress. Plant Cell Environ. 42, 1125-1138. doi: 10.1111/pce.13478

Wang, Y. Q., Yu, W. C., Cao, Y., Lyi, S. M., Wu, W. W., Kang, Y., et al. (2020). An exclusion mechanism is epistatic to an internal detoxification mechanism in aluminum resistance in Arabidopsis. BMC Plant Biol. 20:122. doi: 10.1186/ s12870-020-02338-y

Wang, Z. R., Liu, L., Su, H., Guo, L. Q., Zhang, J. L., Li, Y. F., et al. (2020). Jasmonate and aluminum crosstalk in tomato: identification and expression analysis of WRKYs and ALMTs during JA/Al-regulated root growth. Plant Physiol. Biochem. 154, 409-418. doi: 10.1016/j.plaphy.2020.06.026

Xu, M. Y., Gruber, B. D., Delhaiz, E., White, R. G., James, R. A., You, J. F., et al. (2015). The barley anion channel. HvALMT1, has multiple roles in guard cell physiology and grain metabolism. Physiol. Plant. 153, 183-193. doi: 10.1111/ ppl.12234

Yamaji, N., Huang, C. F., Nagao, S., Yano, M., Sato, Y., Nagamura, Y., et al. (2009). A zinc finger transcription factor artl regulates multiple genes implicated in aluminum tolerance in rice. Plant Cell 21, 3339-3349. doi: 10.1105/tpc.109. 070771

Yang, T. Y., Huang, W. T., Zhang, J., Yang, L. T., Huang, Z. R., Wu, B. S., et al. (2021). Raised pH conferred the ability to maintain a balance between production and detoxification of reactive oxygen species and methylglyoxal in aluminum-toxic Citrus sinensis leaves and roots. Environ. Pollut. 268:115676. doi: 10.1016/j.envpol.2020.115676
Yang, Z. B., He, C., Ma, Y. Q., Herde, M., and Ding, Z. (2016). Jasmonic acid enhances. Al-Induced root growth inhibition. Plant Physiol. 173, 1420-1433. doi: 10.1104/pp.16.01756

Yang, Z. B., Liu, G. C., Liu, J. J., Zhang, B., Meng, W. J., Müller, B., et al. (2017). Synergistic action of auxin and cytokinin mediates aluminum-induced root growth inhibition in Arabidopsis. EMBO Rep. 18, 1213-1230. doi: 10.15252/ embr.201643806

Yao, X., Liu, J., He, X., Liu, H., and Shen, X. F. (2014). Effect of silicon on the morphological and physiological characteristics of peanut seedling under aluminum stress. Chin. J. Oil Crop Sci. 36, 815-818.

Ye, Y., Dai, C. Y., Guo, L. P., Qu, Y., Yang, X. Y., Liu, D. Q., et al. (2018). Salicylic acid reduces the accumulation of aluminum in Panax notoginsen root cell wall pectin via the NO signaling pathway. Plant Soil 430, 171-184. doi: 10.1007/ s11104-018-3722-6

Yin, J. H. (2017). Response of soil moisture to rainfall in pinus massoniana stands and paspalum notatumn glassland in hilly red soil region of southern china. J. Northeast For. Univ. 45, 72-77.

Yuan, H. M., Liu, W. C., Jin, Y., and Lu, Y. T. (2013b). Role of ROS and auxin in plant response to metal-mediated stress. Plant Signal Behavior. 8:e24671. doi: $10.4161 /$ psb. 24671

Zhan, J., Kou, R. J., Li, C. Z., He, H. Y., and He, L. F. (2009). Effects of aluminum on physiological characteristics of mitochondrial membrane in peanut root Tips. Zuo Wu Xue Bao 35, 1059-1067. doi: 10.3724/sp.j.1006.2009.01059

Zhan, J., Kou, R., and He, L. (2008). Effects of aluminum on morphological structure of peanut root tips. Chin. J. Oil Crop Sci. 1, 79-83.

Zhang, D. C., Liu, H. J., Liu, R., and Hao, J. X. (2015). Effect of ultrasonic treatment on nutritional accumulation and antioxidant activity of common buckwheat. Sci. Technol. Food Industry 36:78.

Zhang, J., Kou, R., Li, C., He, H., and He, L. (2009). Effects of aluminum on physiological characteristics of mitochondrial membrane in peanut root tips. Zuo Wu Xue Bao 35, 1059-1067.

Zhang, L., and Hu, H. (2020). Research Progress on the effects of soil acidity and alkalinity on plant growth. Guizhou Agric. Sci. 48, 40-43. doi: 10.1093/jxb/ err194

Zhang, X., Long, Y., Huang, J. J., and Xia, J. J. (2019). Molecular mechanisms for coping with Al toxicity in plants. Int. J. Mol. Sci. 20, 1551-1567. doi: 10.3390/ ijms20071551

Zhang, Y., Zhang, J., Guo, J. L., Zhou, F. L., and Huang, C. F. (2019). F-box protein RAE1 regulates the stability of the aluminum-resistance transcription factor STOP1 in Arabidopsis. Proc. Natl. Acad. Sci. U.S.A. 116, 319-327. doi: 10.1073/pnas. 1814426116

Zheng, W. X., Wu, S. J., and Yang, Y. (2008). Application and prospect of ultrasonic in agriculture. Agric. Outlook 4, 40-42.

Zhu, J., Guo, L. H., and Wang, G. D. (2008). Applications of physical agricultural techniques in fundamental agricultural science and engineering. Coll. Phys. 27, 45-49.

Zhu, X. H., Yang, X. C., and Cai, Y. L. (2005). Fractal and fractal dimension of spatial distribution of china soil system. Tu Rang Xue Bao 42, 881-888.

Conflict of Interest: The authors declare that the research was conducted in the absence of any commercial or financial relationships that could be construed as a potential conflict of interest.

Publisher's Note: All claims expressed in this article are solely those of the authors and do not necessarily represent those of their affiliated organizations, or those of the publisher, the editors and the reviewers. Any product that may be evaluated in this article, or claim that may be made by its manufacturer, is not guaranteed or endorsed by the publisher.

Copyright (c) 2022 Bao, Zhou, Li, Ashraf, Huang, Miao, Cheng, Wan and Zheng. This is an open-access article distributed under the terms of the Creative Commons Attribution License (CC BY). The use, distribution or reproduction in other forums is permitted, provided the original author(s) and the copyright owner(s) are credited and that the original publication in this journal is cited, in accordance with accepted academic practice. No use, distribution or reproduction is permitted which does not comply with these terms. 